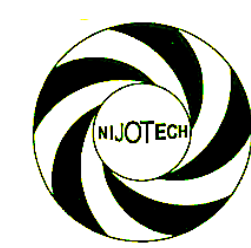

Nigerian Journal of Technology (NIJOTECH)

Vol. 39, No. 3, July 2020, pp. 905 - 910

Copyright@ Faculty of Engineering, University of Nigeria, Nsukka

Print ISSN: 0331-8443, Electronic ISSN: 2467-8821

www.nijotech.com

http://dx.doi.org/10.4314/njt.v39i3.32

\title{
APPLICATION OF 2-DIMENSIONAL TOMOGRAPHY TO INVESTIGATE SUBSURFACE LITHOLOGY IN AUCHI POLYTECHNIC, AUCHI, EDO STATE, NIGERIA
}

\author{
C. O. Aigbogun' ${ }^{1}$ D. A. Babaiwa ${ }^{2, *}$ and B. J. O. Mujakperuo ${ }^{3}$

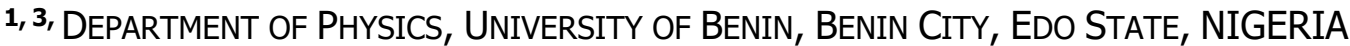

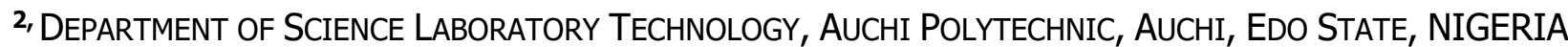 \\ Email addresses: ${ }^{1}$ caigbogun@uniben.edu, ${ }^{2}$ akinbabaiwa@gmail.com, 3 bennykool12@gmail.com
}

\begin{abstract}
The Wenner - Schlumberger array was used for Constant Separation Traversing (CST) to investigate subsurface lithology in Auchi Polytechnic, Auchi. All the traverses were carried out with electrode spacing of $5 \mathrm{~m}$ with a spread of $200 \mathrm{~m}$. The data was obtained using Pasi terrameter (16GL) and processed with the Dipro software. The subsurface resistivity values ranged from $207 \Omega m$ - $8357 \mathrm{\Omega m}$. The results obtained from this survey classified the subsurface lithology into topsoil, clayey sand, sandy clay and sand. The maximum depth penetrated was $50 \mathrm{m.}$
\end{abstract}

Keywords: Lithology, resistivity, subsurface, Wenner-Schlumberger, 2-Dimensional.

\section{INTRODUCTION}

Water they say, is life. If water is life, all attempts to develop, manage and sustain it should be worth the while. It is worrisome that existing boreholes are not functioning at their maximum yield in the study area. It is for this reason, that this study was carried out with the aim of using the information obtained from the subsurface lithology for aquifer characterization and to act as a guide in the event of drilling boreholes. A more accurate model of the subsurface is a twodimensional (2-D) model where the resistivity changes in the vertical direction, as well as in the horizontal direction along the survey line. In this case, it is assumed that resistivity does not change in the direction that is perpendicular to the survey line. In many situations, particularly for surveys over elongated geological bodies, this is a reasonable assumption [1]. However, at the present time, 2-D surveys are the most practical economic compromise between obtaining very accurate results and keeping the survey costs down [2].

The resistivity of the 2D model is assumed to vary both vertically and laterally along the survey line but constant in the direction perpendicular to the survey line. The observed apparent resistivity values are commonly presented in pictorial form using pseudosection contouring (Figure 3 - 6) which gives an approximate picture of the subsurface resistivity distribution. The shape of the contours depends on the type of array used in the investigation as well as the distribution of the true subsurface resistivity. The pseudosection plot serves as a useful guide for a detailed quantitative interpretation. Poor apparent resistivity measurements can easily be identified from the pseudosection plot. The pseudo-depth values are based on the sensitivity values or the Frechet derivatives for a homogenous half-space [3]. Twodimensional (2D) geoelectrical resistivity imaging has been extensively employed to map areas with moderately complex geology [4-9].

Loke [1] stated that the major limitation of the 2D geoelectrical resistivity imaging is that measurements made with large electrode spacing are often affected by the deeper sections of the subsurface as well as structures at a larger horizontal distance from the survey line. It is most distinct when the survey line is placed near a steep contact with the line parallel to the contact.

The aim of this study therefore, is to determine the resistivity distribution and delineate the subsurface lithology using 2-D imaging. 


\section{MATERIALS AND METHODOLOGY}

\subsection{Location of the study area.}

The geophysical survey was carried out in Auchi Polytechnic, Auchi. The first location being Auchi Poly staff primary school, and has the following coordinates: Latitude $07^{\circ} 03^{\prime} 42.2^{\prime \prime}$ and Longitude $006^{\circ}$ $16^{\prime} 14.7^{\prime \prime}$. These coordinates were obtained using Garmin 12 Global positioning system (GPS). Actual site observation and information from existing geological maps classify surface sand of the study area and its environs as members of the Ajali formation [10].

\subsection{Theory of experiment}

This is an integration of the Wenner and Schlumberger arrays employed in electrical imaging surveys $/ 2 \mathrm{D}$.

Two-dimensional (2D) geoelectrical resistivity imaging can be achieved by integrating the techniques of vertical electrical sounding with that of electrical profiling. It involves apparent resistivity measurements from electrodes placed along a line using a range of different electrode separations and midpoints. The procedure is repeated for as many combinations of current and potential electrode positions as defined by the survey configuration. 2D resistivity imaging can be seen as continuous vertical electrical sounding (CVES) in which a number of VES conducted in a grid are merged together or as a combination of successive profiles with increasing electrode spacing.

Two-dimensional (2D) resistivity surveys are usually carried out using large numbers of electrodes connected to multi-core cables. For a system with limited number of electrodes, the area covered by the survey can be extended along the survey line using the roll-along technique [12].

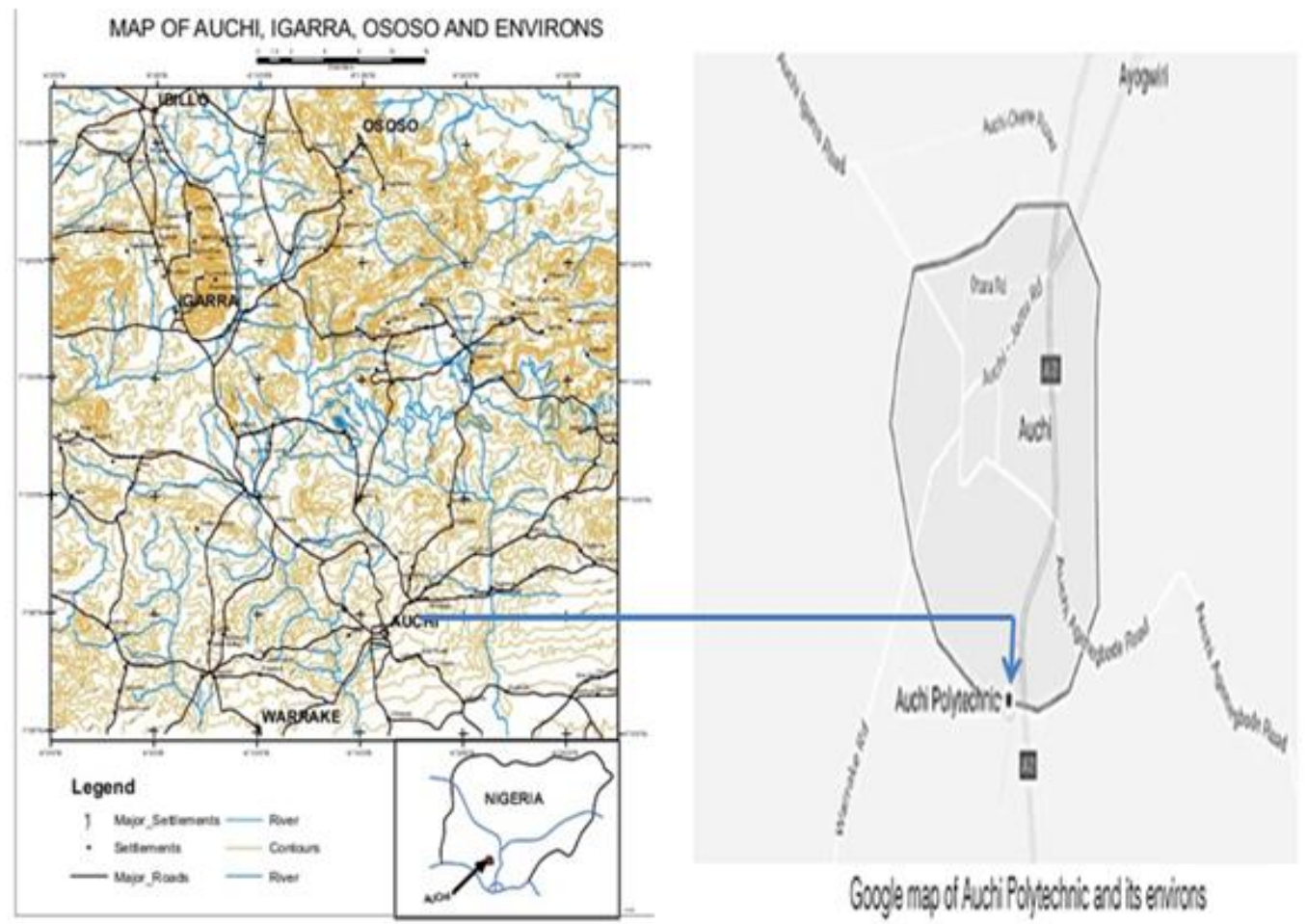

Figure 1: Geophysical map of Auchi [1]

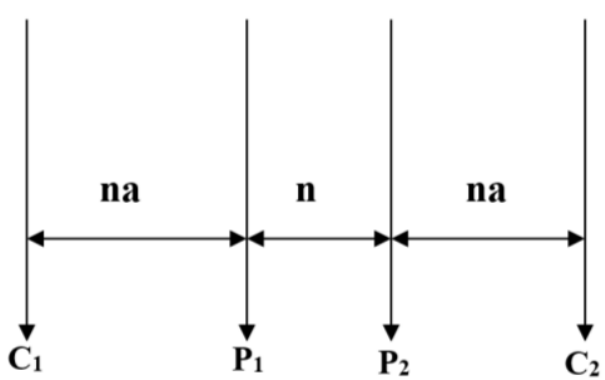

$\mathrm{K}=\mathrm{nn}(\mathrm{n}+1) \mathrm{a}$

Where $\mathrm{k}=$ geometric factor

$\Pi=$ constant

$\mathrm{a}=$ dipole length

$C_{1}$ and $C_{2}=$ current electrodes

$\mathrm{P}_{1}$ and $\mathrm{P}_{2}=$ potential electrodes

$\mathrm{n}=$ dipole separation factor

Figure 2: Wenner-Schlumberger configuration 
This can be achieved by moving the cables past one end of the line by several units of electrode spacing, after completing a sequence of measurements.

Four (4) different locations were surveyed in the study area using the $2 \mathrm{D}$ electrical resistivity tomography. The Wenner-Schlumberger configuration was adopted in preference to the other configurations because of its good vertical resolution and wider horizontal data coverage with the use of Pasi terrameter (16-GL). The electrodes were arranged with a constant spacing of $5 \mathrm{~m}$. The " $\mathrm{n}$ " factor is the ratio of the distance between the $C_{1}-P_{1}$ (or $P_{2}-C_{2}$ ) electrodes to the spacing between the $P_{1}$ - $\mathrm{P}_{2}$ potential pair [1].

The data obtained were transferred to the computer for processing and inversion using DIPROfWin Software 4.01. The software inverts the data using the smoothness-constrained least-squares inversion algorithm to achieve stable results. The program uses the active constraint balancing (ACB) method which accounts for the use of variable Lagrangian multiplier at each of the parameterized blocks of the model during the inversion process to enhance both resolution and stability [13].

\section{RESULTS AND DISCUSSION}

The results are presented in a colour coded format consisting of the inverted $2 \mathrm{D}$ resistivity tomography. The horizontal scale on the image is the lateral distance while the vertical scale is the depth and both are in metres. A maximum spread of $190 \mathrm{~m}$ with the corresponding depth of $50 \mathrm{~m}$ was investigated and modeled on the profiles as shown in Figure 3.

\subsection{Location one}

The $2 \mathrm{D}$ resistivity image in location one is presented in Figure 3. Three (3) distinct resistivity images indicating sandy clay topsoil, clayey sand and sand are revealed. The sandy clay topsoil is fairly continuous with the thickness varying from 0 to $5 \mathrm{~m}$ and resistivity values ranging from $207-4814 \Omega \mathrm{m}$. The clayey sand thickness varies from 5 to $15 \mathrm{~m}$ and resistivity values which vary from $999-2183 \Omega \mathrm{m}$. The basal sand thickness varies from 30 to $35 \mathrm{~m}$ and the resistivity values vary from $3394-4817 \Omega$ m. From the lithologs and geoelectric sections generated from the vertical electrical sounding (VES) done on the same site by [14], there appears to be some correlation. The VES resistivity distribution varies from $147.3-1756 \Omega \mathrm{m}$ with a thickness of $3.5-7.0$ $\mathrm{m}$. It reveals topsoil that is clayey sand, underlain by sandy clay and sand. This correlation provides a better subsurface understanding of the lithological sequence of the study area. Generally, across the study area, the high resistivity values across each resistivity image are due to the geologic age of the formations underlying the study area. These formations belong to the Maastrichtian age with likely high indurations [15].

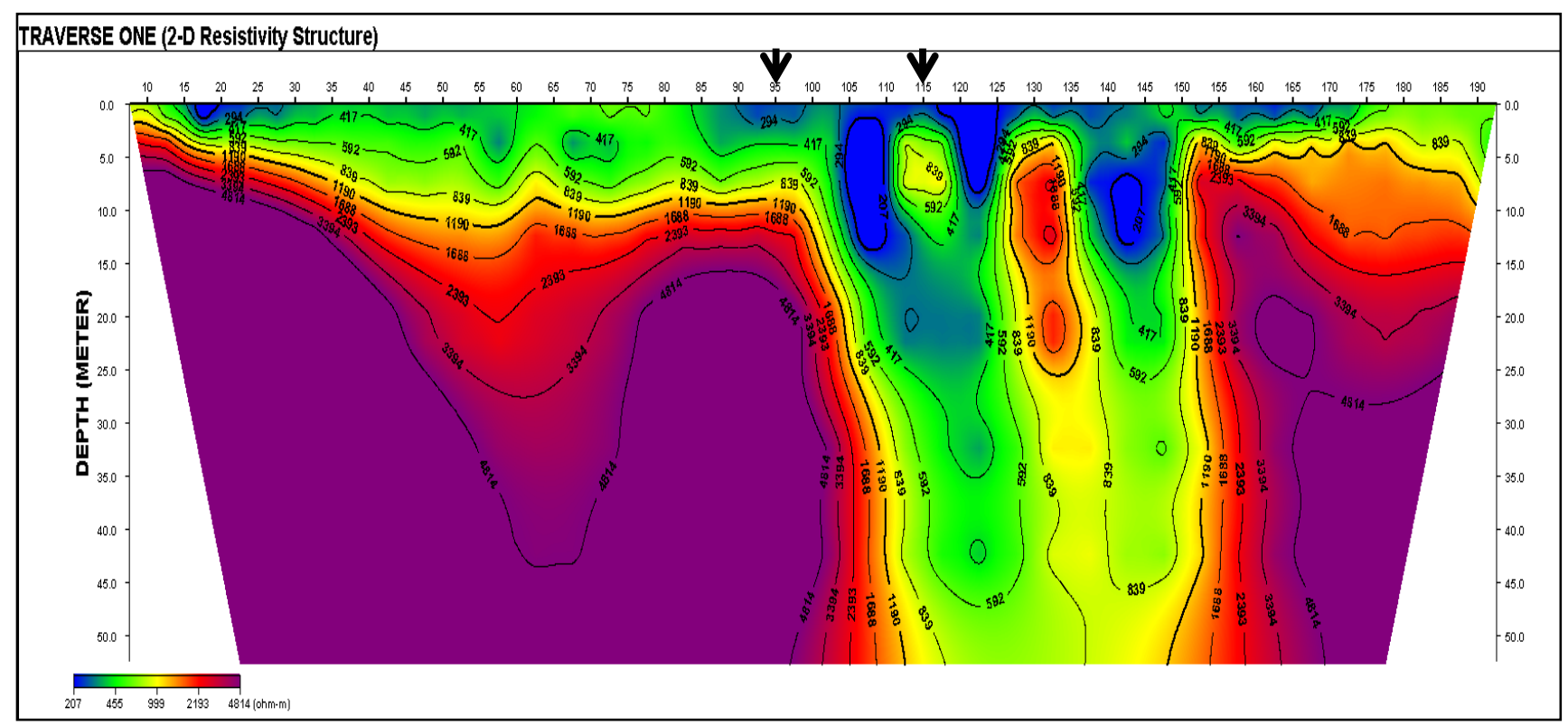

Figure 3: Resistivity image in location one. 


\subsection{Location two}

A total spread of $200 \mathrm{~m}$ was surveyed and a depth of $50 \mathrm{~m}$ was investigated with resistivity values ranging from 409 to $8357 \Omega \mathrm{m}$ as shown in Figure 4. Three resistivity images which signified sandy clay topsoil, clay and sand are revealed on the 2D image. The resistivity values of the topsoil (sandy clay) vary from 889 to $1849 \Omega \mathrm{m}$ and the thickness varies from 0 to 5 $\mathrm{m}$. The topsoil is fairly continuous with sandy resistivity image being visible between 125 and 170 $\mathrm{m}$ horizontal distance along the traverse. The clayey structure exists in three isolated pockets across the traverse at a depth range of 3 to $10 \mathrm{~m}$ and at horizontal distances of 55 to $65 \mathrm{~m}, 80$ to $85 \mathrm{~m}$ and 150 to $175 \mathrm{~m}$. The resistivity and thickness values of the clay vary from 409 to $572 \Omega \mathrm{m}$ and 3 to $35 \mathrm{~m}$ in the subsurface. The sand varies in resistivity and thickness values from 3931 to $8357 \Omega m$ and 5 to 40 $\mathrm{m}$ respectively. The resistivity distribution from the VES results according to [14] varies from 1891 $9404.0 \Omega \mathrm{m}$ and the thickness from 21.1 - $107.2 \mathrm{~m}$; showing topsoil that is clayey sand, followed by sandy clay, sand and dry sandstone. The high range of resistivity values is due to reasons given in location one.

\subsection{Location three}

A total spread of $200 \mathrm{~m}$ was surveyed and a depth of $50 \mathrm{~m}$ was investigated with resistivity values ranging from 634 to $4750 \Omega \mathrm{m}$ as shown in Figure 5 . Four distinct resistivity images which denote sandy clay/sandy topsoil, clay, clayey sand, and sand are shown on the 2D image. The sandy clay/sandy topsoil is fairly continuous with the thickness varying from 0 to $5 \mathrm{~m}$ and resistivity values ranging from 1049 to $3798 \Omega \mathrm{m}$. The thickness of the clay varies from 15 to $40 \mathrm{~m}$ and resistivity values which vary from 634 to $793 \Omega \mathrm{m}$. The clay structure exists in three isolated zones in the subsurface along 30 to $60 \mathrm{~m}$; 105 to $125 \mathrm{~m}$ and 170 to $200 \mathrm{~m}$ lateral distances and at a depth range of 7 to $10 \mathrm{~m}$ in the subsurface. The clayey sand with resistivity values and thickness ranging from 1049 to $2871 \Omega \mathrm{m}$ and 3 to $40 \mathrm{~m}$ respectively, are well distributed across this traverse, thus indicating a high degree of heterogeneity of the subsurface configuration. The resistivity of the sand varies from 3037 to $4780 \Omega \mathrm{m}$ and the thickness varies from 10 to $40 \mathrm{~m}$ in different isolated zones in the subsurface. The resistivity distribution from the VES results ranges from $198.3-451.9 \Omega \mathrm{m}$ with thickness varying from $0.5-0.7 \mathrm{~m}$; subsurface lithology corresponds to clay/clayey sand, sandy clay and sand.

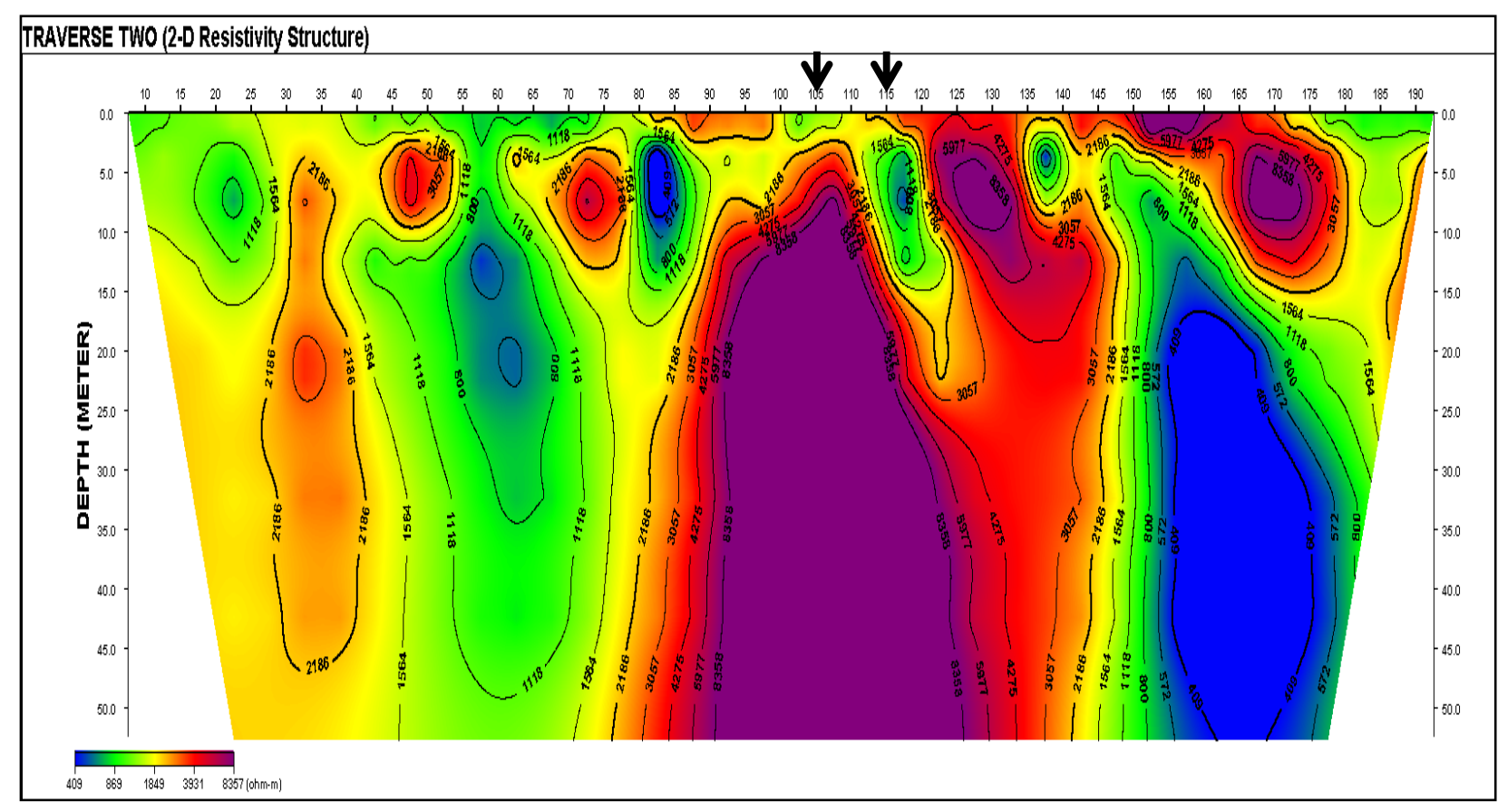

Figure 4: Resistivity image in location two 


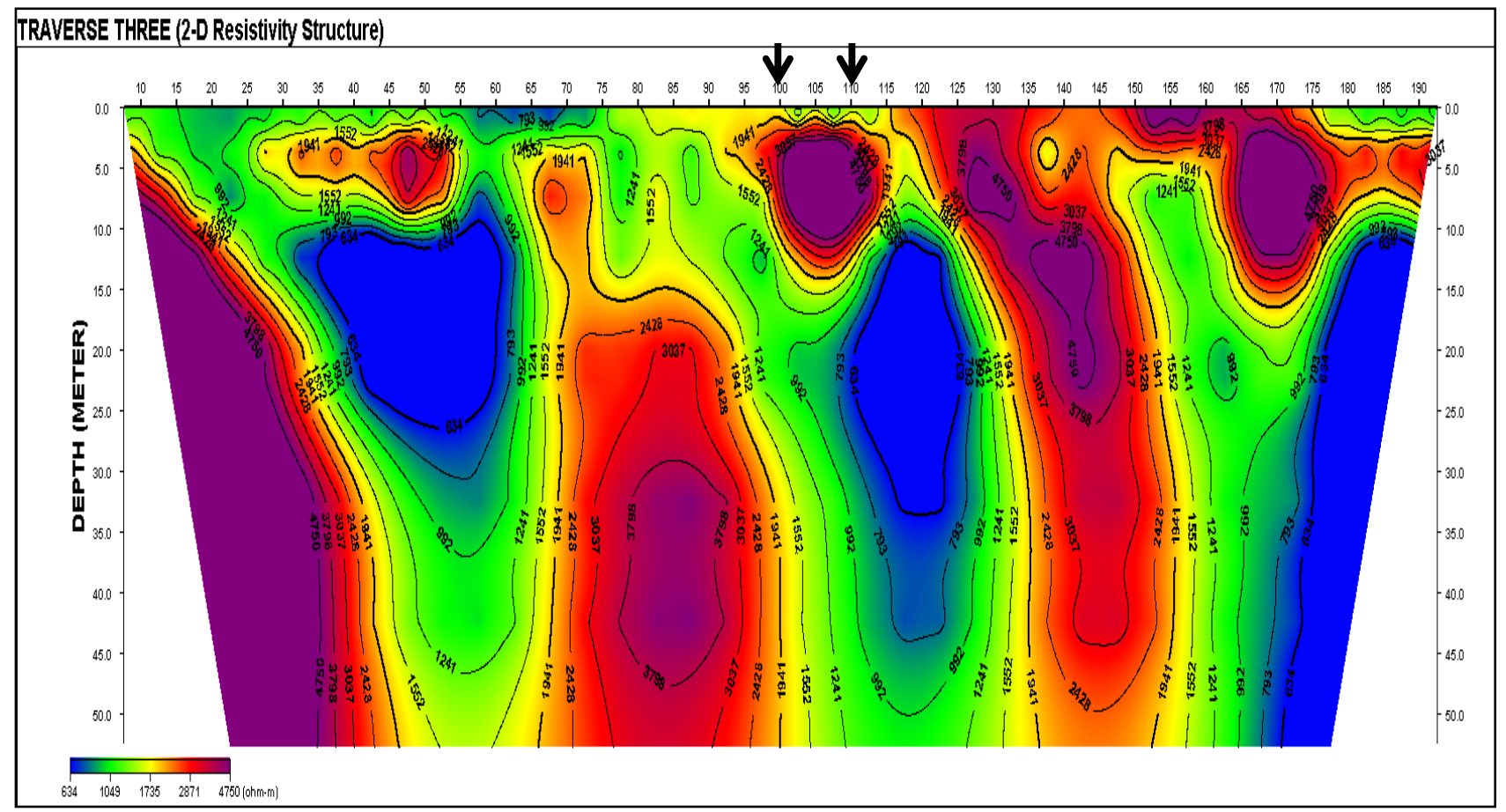

Figure 5: Resistivity image in location three

\subsection{Location four}

A total spread of $200 \mathrm{~m}$ was surveyed and a depth of $50 \mathrm{~m}$ was probed with resistivity values ranging from 232 to $5910 \Omega m$ as shown in Figure 6. Four (4) resistivity images which are representative of topsoil (clayey/sandy clay), clay, clayey sand, and sand are shown on the 2D image. The clay/sandy clay topsoil is fairly continuous with resistivity and the thickness ranging from 232 to $522 \Omega \mathrm{m}$ and 3 to $10 \mathrm{~m}$ respectively. The clay varies in resistivity from 233 to $333 \Omega \mathrm{m}$ and in thickness from 3 to $40 \mathrm{~m}$ in the two localized zones along the traverse. The clayey sand resistivity image varies in resistivity and thickness values from 684 to $1403 \Omega \mathrm{m}$ and 5 to $20 \mathrm{~m}$ respectively. The resistivity values of the sand vary from 2632 to $5910 \Omega \mathrm{m}$ and the thickness varies from 20 to $45 \mathrm{~m}$. The resistivity distribution from the VES results according to [14] varies from $823.0-4412.5$ $\Omega \mathrm{m}$ and the thickness from $6.9-41.8 \mathrm{~m}$; showing topsoil that is clayey sand, followed by sandy clay and sand.

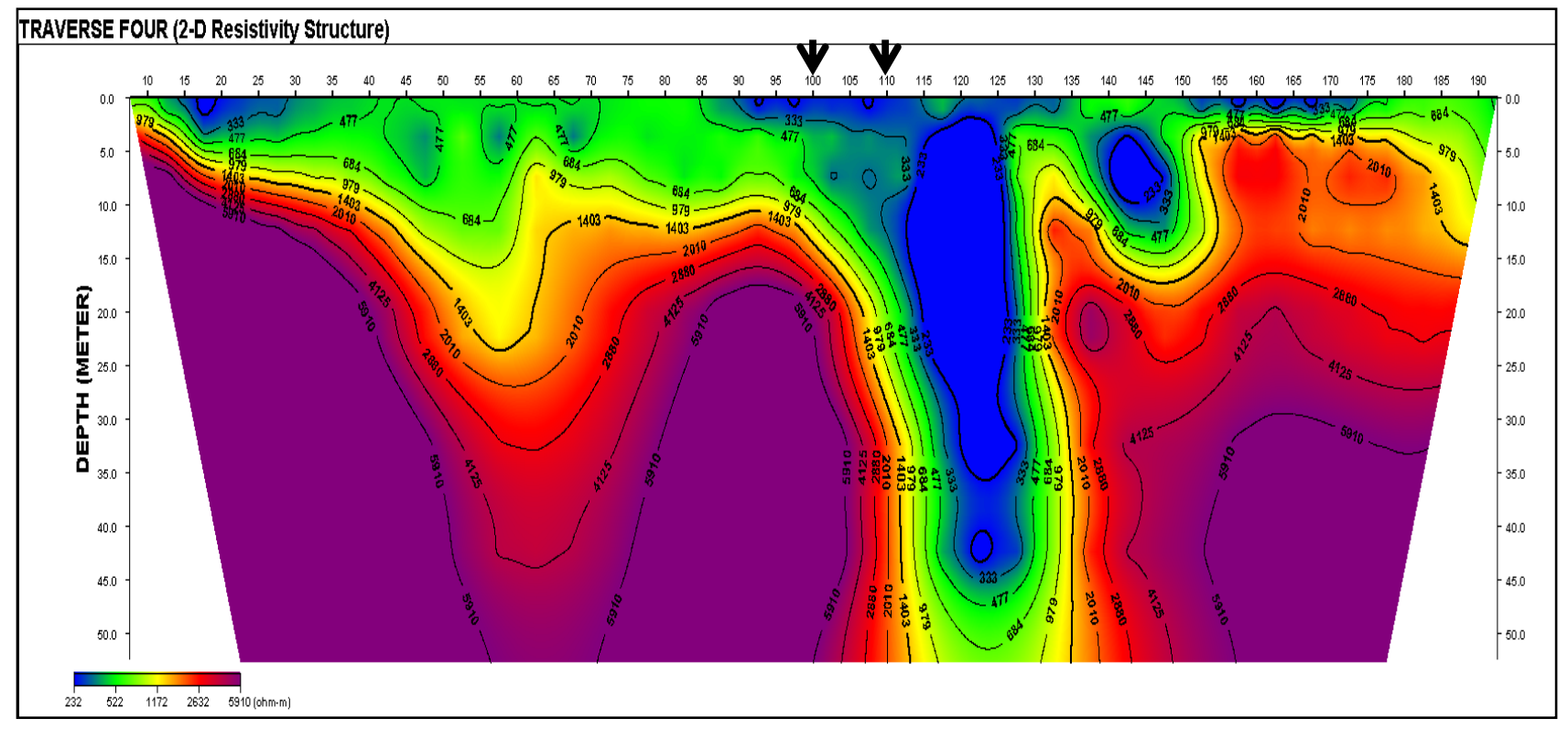

Figure 6: Resistivity image in location four 


\section{CONCLUSION}

In this study, the 2D resistivity tomography has succeeded in revealing the lateral and vertical subsurface information with resistivity values for the topsoil ranging from 233 to $3798 \Omega \mathrm{m}$ with a thickness of $0-1 \mathrm{~m}$ The second layer signifying clayey sand has resistivity values ranging from 207 to $8357 \Omega m$ with a thickness of $10 \mathrm{~m}$. The third layer with resistivity values ranging from 233 to $5910 \Omega \mathrm{m}$ represents sandy clay with a thickness of $40 \mathrm{~m}$. The fourth horizon represents sand with resistivity values ranging from 1891 to $9404 \Omega \mathrm{m}$ with a thickness of 50 $\mathrm{m}$.

\section{REFERENCES}

[1] Loke, M.H. Electrical Imaging Surveys for Environmental and Engineering Studies: $A$ Practical Guide to 2D and 3D surveys, 2001.

[2] Dahlin T, and Loke, M.H. "Quasi-3D resistivity imaging-mapping of three-Dimensional structures using two-dimensional DC resistivity techniques". Proceedings of the 3rd Meeting of the Environ. Eng. Geophy. Soc., 1997, pp. 143146.

[3] Aizebeokhai, A.P. "2D and 3D Geological Resistivity Imaging: Theory and Field Design". Scientific Research and Essays Vol.5 (23), 2010, pp. $3592-3605$.

[4] Griffiths, D.H. and Barker, R.D. "Two dimensional resistivity imaging and modelling in areas of complex geology". J. Appl. Geophy., 29, 1993, pp. 211- 226.

[5] Griffiths, D.H., Turnbull, J. and Olayinka, A.I. "Two-dimensional resistivity mapping with a complex controlled array". First Break, 8(4), 1990, pp. 121-129.

[6] Dahlin, T. and Loke, M.H. "Resolution of 2D Wenner resistivity imaging as assessed by numerical modeling". J Appl Geophys 38 (4), 1998, pp. 237-248.

[7] Olayinka, A.I. "Advantage of two-dimensional geoelectrical imaging for Groundwater prospecting: case study from Ira, southwestern Nigeria". Water Res. J. Nig. Assoc. Of Hydrogeol., 10, 1999a, pp. 55-61.

[8] Olayinka, A.I. and Yaramanci U. "Choice of the best model in 2-D geoelectrical imaging: case study from a waste dump site". Eu. J. Environ. Eng. Geophy.,3, 1999b, pp. 221-244.

[9] Amidu, S., and Olayinka, A.I. "Environmental assessment of sewage disposal Systems using 2D electrical resistivity imaging and geochemical analysis: A case study from Ibadan, Southwestern Nigeria". Journal of Environment. Engineering and Geosciences., 7(3), 2006, pp. 261-272.

[10] Alile, O.M., Amadasun, C. V. O., and Evbuomwan, A. I. "Application of vertical electrical sounding method to decipher the existing subsurface stratification and groundwater occurrence status in a location in Edo North of Nigeria". International Journal of Physical Sciences, Vol. 3 (10), 2008, pp. 245249.

[11] Umoru, A.T., Oyathelemi, E.O., and Sule, T.U.N. "Ground water research and development in Auchi Polytechnic, Auchi", Journal of Civil and Environmental Research. Vol. 3, No 8, 2013, pp. 32-34.

[12] Dahlin, T, and Bernstone, C. "A roll-along technique for 3D resistivity data acquisition with multi-electrode arrays". Proceedings of SAGEEP'97, Reno, Nevada, 1997, pp. 927-935.

[13] Aminu, M.B., Akande, T.M. and Ishola, O.A. "2D Geoelectric Imaging of the Uneme-Nekhua Fracture Zone". International Journal of Geophysics, Vol. 2014. pp. 1-8

[14] Babaiwa, D.A; Aigbogun, C.O. and Umoru, A.T. "Aquifer characterization Using vertical electrical sounding in Auchi Polytechnic, Auchi, Edo State, Nigeria. (Accepted)

[15] Umeji, P.O and Nwajide, C.S. "Age control and designation of the standard stratotype Of Nsukka formation of Anambra Basin, Southeastern Nigeria". Journal of Mining and Geology 43 (2), 2007, pp. 147 - 166. 